\title{
Hybrid Dislocated Control and General Hybrid Projective Dislocated Synchronization for Memristor Chaotic Oscillator System
}

\author{
Junwei Sun, ${ }^{1,2}$ Chun Huang, ${ }^{1,2}$ and Guangzhao Cui ${ }^{1,2}$ \\ ${ }^{1}$ College of Electric and Information Engineering, Zhengzhou University of Light Industry, Zhengzhou 450002, China \\ ${ }^{2}$ Henan Key Lab of Information-Based Electrical Appliances, Zhengzhou University of Light Industry, Zhengzhou 450002, China \\ Correspondence should be addressed to Junwei Sun; junweisun@yeah.net
}

Received 1 June 2014; Revised 4 September 2014; Accepted 9 September 2014; Published 16 October 2014

Academic Editor: M. Lakshmanan

Copyright ( $\odot 2014$ Junwei Sun et al. This is an open access article distributed under the Creative Commons Attribution License, which permits unrestricted use, distribution, and reproduction in any medium, provided the original work is properly cited.

Some important dynamical properties of the memristor chaotic oscillator system have been studied in the paper. A novel hybrid dislocated control method and a general hybrid projective dislocated synchronization scheme have been realized for memristor chaotic oscillator system. The paper firstly presents hybrid dislocated control method for stabilizing chaos to the unstable equilibrium point. Based on the Lyapunov stability theorem, general hybrid projective dislocated synchronization has been studied for the drive memristor chaotic oscillator system and the same response memristor chaotic oscillator system. For the different dimensions, the memristor chaotic oscillator system and the other chaotic system have realized general hybrid projective dislocated synchronization. Numerical simulations are given to show the effectiveness of these methods.

\section{Introduction}

Memristor is considered to be the missing 4 th passive circuit element postulated in 1971 [1]. And it took scientists almost 40 years to invent such a practical device until a team at HewlettPackard Labs announced the development of a memristor in Science on May 1, 2008 [2], by titanium dioxide thin films. Memristor takes its place along other three existing elements such as the resistor, capacitor, and inductor and shares many properties of resistors such as the unit of measurement ohms.

Chaos is an important nonlinear phenomenon and can be observed in many practical applications of various fields, including biology, chemistry, and engineering. Since the effect of chaotic system is usually undesirable, irregular, and unpredicted due to its sensitivity to initial conditions, it is necessary that the chaotic dynamics of a system can be controlled. During the last several decades, controlling chaotic systems have been widely studied due to undesirable or harmful chaotic behaviors under many circumstances. Controlling chaos has been focused on by many researchers since Ott, Grebogi, and Yorke proposed an efficient method, called the OGY method [3]. Several theoretical methods have been developed to realize chaos synchronization such as feedback control method [4], active control method [5], backstepping method [6], adaptive control method [7-12], sliding mode control method [13], impulsive control method [14], and coupling control method [15].

Now, the research on circuits based on memristor is becoming a hot topic for research. Chaotic oscillator system containing memristor also attracts attention recently [1620]. Various methods are used to suppress chaos. Zhong et al. have investigated the issues of fuzzy modeling and impulsive control of a memristor chaotic system and presented a memristor chaotic system as the Takagi-Sugeno model-based fuzzy system [21]. The chaotic system could be stabilized by a switched feedback controller which can be obtained by solving a set of LMIs [22]. Chaos of a memristor-based Chua's oscillator has been controlled by backstepping method [23]. A twin-T notch filter feedback controller has been designed and employed to control the chaotic behavior in the memristor-based chaotic circuit [24]. To the best of the author's knowledge, four-dimensional 
chaotic system has rarely been studied; the synchronization for four-dimensional chaotic system has rarely been studied for the researchers.

Motivated by the existing works, we focus on not only the chaotic control of the memristor chaotic oscillator system but also a novel hybrid dislocated control synchronization scheme. Some important dynamical properties of the memristor chaotic oscillator system have been studied in the paper. Based on the Lyapunov stability theorem, a novel hybrid dislocated control method and a general hybrid projective dislocated synchronization scheme have been realized for memristor chaotic oscillator system.

Firstly, some important dynamical properties of the memristor chaotic oscillator system have been gained in Section 2; then, in Section 3, hybrid dislocated control method for stabilizing chaos to unstable equilibrium is realized. Section 4 realizes general hybrid projective dislocated synchronization for the memristor chaotic oscillator systems. Several illustrative examples are given in Section 5; finally, a brief concluding summary will be given in Section 6 .

\section{The Memristor Chaotic Oscillator and Dynamical Analysis}

Recently, Chua [1] introduced a memristor chaotic system by replacing Chua's diode in the well-known Chua's chaotic system. A memristor chaotic system is extended from Chua's oscillator using a piece-wise linear memristor [22]; $q(w)$ is a piece-wise linear function of the form

$$
q(w)=b w+0.5(a-b)(|w+1|-|w-1|),
$$

where $a, b>0 . \varphi(w)$ is provided in the following expression:

$$
\varphi(w)=\frac{d q(w)}{d w}= \begin{cases}a, & |w|<1 \\ b, & |w|>1\end{cases}
$$

By applying Kirchhoff's circuit laws to the memristor Chuas circuit in Figure 1, the following state equation is gained:

$$
\begin{aligned}
\dot{v}_{1} & =\frac{1}{c_{1}}\left[i-\varphi(w) v_{1}\right], \\
\dot{v}_{2} & =\frac{1}{c_{2}}\left(G v_{2}-i\right), \\
i & =v_{2}-v_{1}-i R, \\
\dot{\varphi} & =v_{1},
\end{aligned}
$$

where $v_{1}$ and $v_{2}$ represent the voltages across the capacitors $c_{1}$ and $c_{2}$, while $i$ is the current through the inductor $L . R, G$ are the circuit parameters. Set $x_{1}=v_{1}, x_{2}=v_{2}, x_{3}=i, x_{4}=\varphi$,

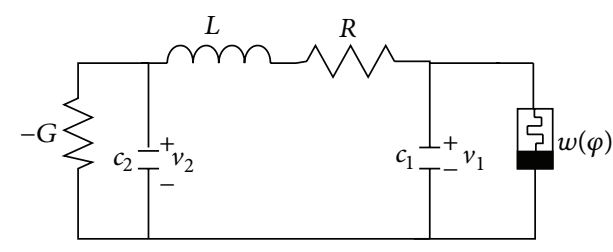

FIgURE 1: Chaotic system with memristor.

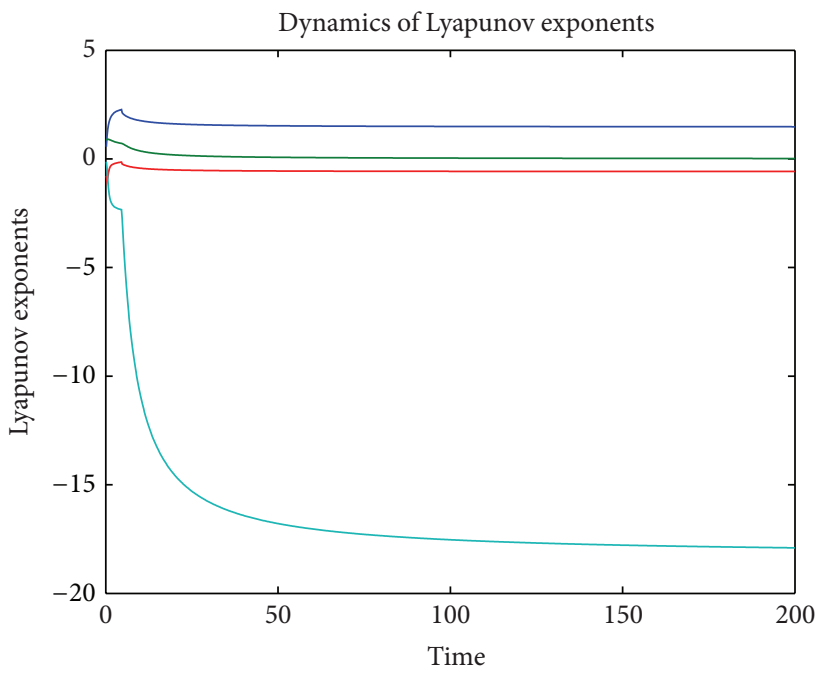

FIGURE 2: The Lyapunov exponents.

$a_{1}=1 / c_{1}, a_{2}=G / c_{2}, a_{3}=1 / c_{2}$, and $a_{4}=R$; then, the system can be further extended by the following expression:

$$
\begin{aligned}
& \dot{x}_{1}=a_{1}\left[x_{3}-\varphi\left(x_{4}\right) x_{1}\right], \\
& \dot{x}_{2}=a_{2} x_{2}-a_{3} x_{3}, \\
& \dot{x}_{3}=x_{2}-x_{1}-a_{4} x_{3}, \\
& \dot{x}_{4}=x_{1} .
\end{aligned}
$$

2.1. The Lyapunov Dimension, the Lyapunov Exponents, and Spectra. Assume $a_{1}=5.1, a_{2}=0.69, a_{3}=1, a_{4}=0.12$, $a=0.2$, and $b=17.8$; the Lyapunov exponents of this chaotic system are computed by the time-series method for the initial condition $\left(10^{-4}, 0,0,0\right)$. Corresponding Lyapunov exponents are $L_{1}=1.479485, L_{2}=0, L_{3}=-0.580770$, and $L_{4}=-17.903521$, as in Figure 2. It is obvious that there exists one positive exponent and the sum of the exponents is negative, and the Lyapunov dimension is given by

$$
d_{L}=j-\frac{1}{L_{j+1}} \sum_{i=1}^{j} L_{i}=3-\frac{L_{1}+L_{2}+L_{3}}{L_{4}}=3.05,
$$

where $j$ is the largest integer for

$$
\sum_{i=1}^{j} L_{i}>0, \quad \sum_{i=1}^{j+1} L_{i}<0 .
$$

System (4) is chaotic with the 2-scroll attractor in Figures 3 , 4,5 , and 6 . 


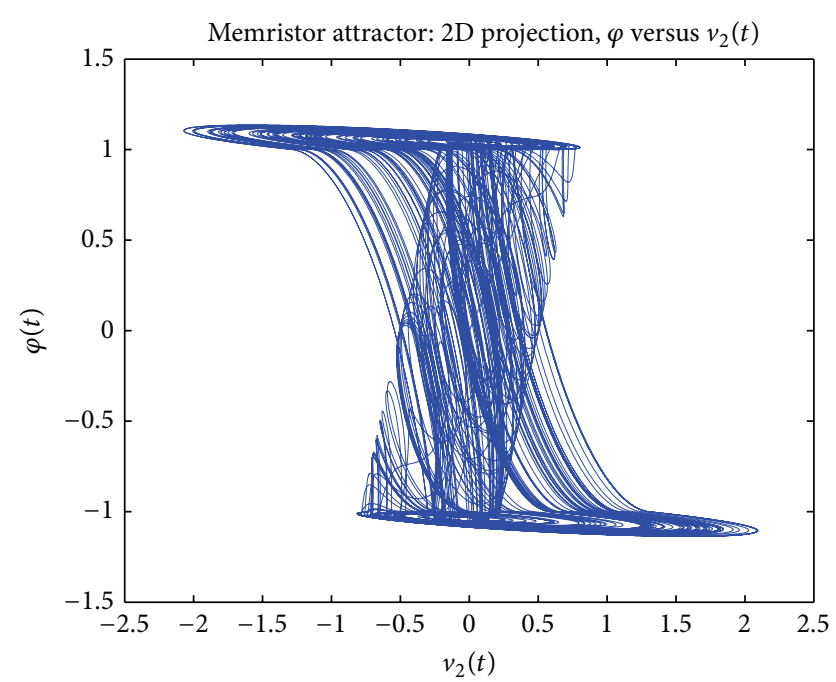

FIGURE 3: Chaotic attractor of system (3).

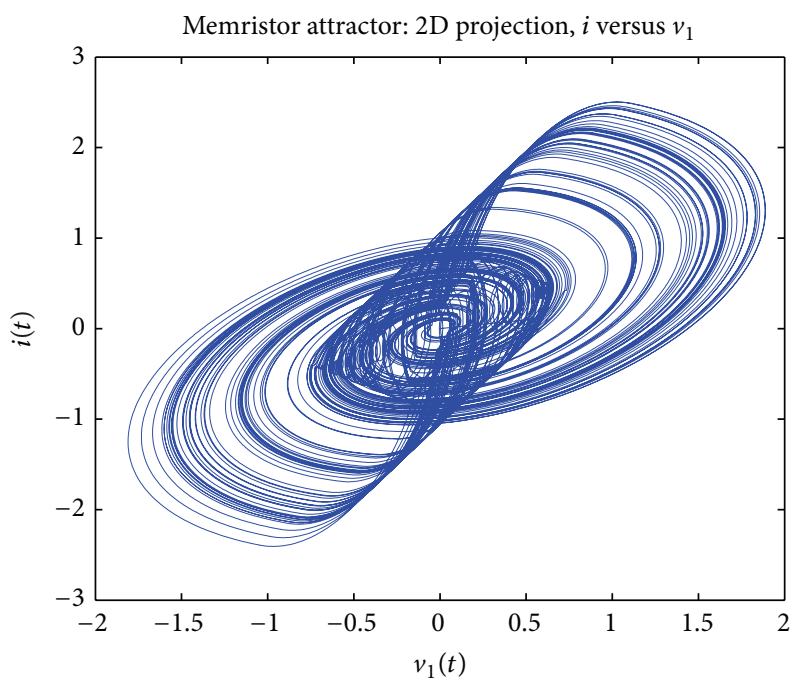

FIGURE 4: Chaotic attractor of system (3).

2.2. Dissipativity and Attractor. For system (4), the following expression is given by

$$
\begin{aligned}
\nabla(V) & =\frac{\partial \dot{x}_{1}}{\partial x_{1}}+\frac{\partial \dot{x}_{2}}{\partial x_{2}}+\frac{\partial \dot{x}_{3}}{\partial x_{3}}+\frac{\partial \dot{x}_{4}}{\partial x_{4}} \\
& =-a_{1} \varphi\left(x_{4}\right)+a_{2}-a_{4}
\end{aligned}
$$

Therefore, $f=-a_{1} \varphi\left(x_{4}\right)+a_{2}-a_{4}=-1.59$ or $-91.35<$ 0 , so system (4) is dissipative. It converges the exponential convergence form

$$
\frac{d V}{d t}=e^{f}
$$

This is to say, as $t \rightarrow \infty, V_{0}$ is reduced to $V_{0} e^{f t}$. In other words, any volume element with the system line is contracted to 0 with the exponential convergence rate. Thus, all system

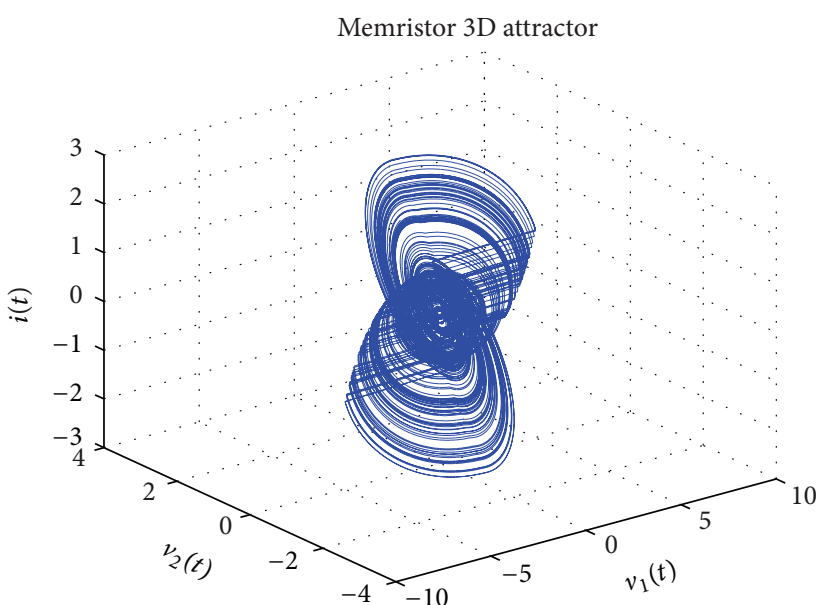

FIgURE 5: Chaotic attractor of system (3).

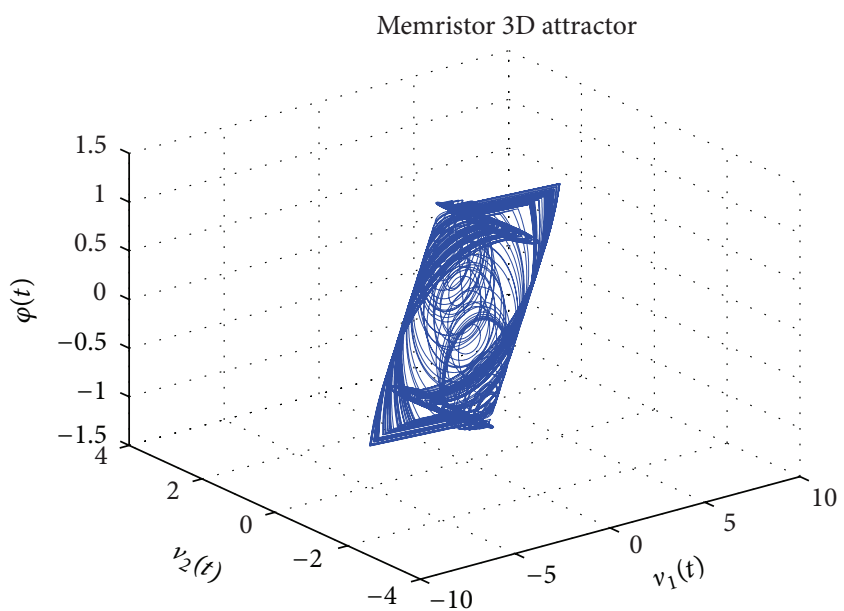

FIgURE 6: Chaotic attractor of system (3).

trajectories are limited to a specific subset of volume 0 . The system has an attractor, and it may have very complex geometry.

\section{Controlling Chaos with Hybrid Dislocated Control Method}

Definition 1. For the controlled chaotic system

$$
\dot{x}=f(x),
$$

where $x=\left(x_{1}, x_{2}, \ldots, x_{n}\right)^{T} \in R^{n}$ is a state vector and $f$ : $R^{n} \rightarrow R^{n}$ is a continuous vector function, let

$$
\begin{aligned}
\dot{x}_{i}= & f\left(x_{i}\right)+k_{1}\left(x_{1}-p_{1}\right)+\cdots+k_{i-1}\left(x_{i-1}-p_{i-1}\right) \\
& +k_{i+1}\left(x_{i+1}-p_{i+1}\right)+\cdots+k_{n}\left(x_{n}-p_{n}\right),
\end{aligned}
$$

where $k_{i}(i=1,2, \ldots, n)$ are constants and $x_{E_{i}}=\left(p_{1}, p_{2}, \ldots\right.$, $\left.p_{n}\right)$ stands for the equilibrium point of the original system $\dot{x}=f(x)$. If there at least exists a constant $k_{i} \neq 0$, such that the chaotic trajectories of system (4) can be successfully driven 
to the equilibrium point $x_{E_{i}}$, then hybrid dislocated control original system is achieved.

Remark 2. For the three-dimensional chaotic system that is given as follows:

$$
\begin{aligned}
& \dot{x}_{1}=f_{1}\left(x_{1}, x_{2}, x_{3}\right), \\
& \dot{x}_{2}=f_{2}\left(x_{1}, x_{2}, x_{3}\right), \\
& \dot{x}_{3}=f_{3}\left(x_{1}, x_{2}, x_{3}\right),
\end{aligned}
$$

where $x=\left(x_{1}, x_{2}, x_{3}\right)^{T} \in R^{3}$ is the state vector and $f: R^{3} \rightarrow$ $R^{3}$ is the continuous vector function, let

$$
\begin{aligned}
& \dot{x}_{1}=f_{1}\left(x_{1}, x_{2}, x_{3}\right)+k_{3}\left(x_{3}-p_{3}\right), \\
& \dot{x}_{2}=f_{2}\left(x_{1}, x_{2}, x_{3}\right)+k_{1}\left(x_{1}-p_{1}\right), \\
& \dot{x}_{3}=f_{3}\left(x_{1}, x_{2}, x_{3}\right)+k_{2}\left(x_{2}-p_{2}\right),
\end{aligned}
$$

or

$$
\begin{aligned}
& \dot{x}_{1}=f_{1}\left(x_{1}, x_{2}, x_{3}\right)+k_{2}\left(x_{2}-p_{2}\right), \\
& \dot{x}_{2}=f_{2}\left(x_{1}, x_{2}, x_{3}\right)+k_{3}\left(x_{3}-p_{3}\right), \\
& \dot{x}_{3}=f_{3}\left(x_{1}, x_{2}, x_{3}\right)+k_{1}\left(x_{1}-p_{1}\right),
\end{aligned}
$$

where $k_{i}(i=1,2, \ldots, n)$ are constants and $\left(p_{1}, p_{2}, p_{3}\right)$ stands for the equilibrium point of the original system (11).

Remark 3. Generally, the controller of chaotic system is given to every state variable. Hybrid dislocated control method need not consider the place of the controller.

3.1. Stabilizing the Equilibrium Point with Hybrid Dislocated Control Method. System (4) is changed into the following controlled memristor chaotic oscillator system:

$$
\begin{aligned}
& \dot{x}_{1}=a_{1}\left[x_{3}-\varphi\left(x_{4}\right) x_{1}\right]+u_{1}, \\
& \dot{x}_{2}=a_{2} x_{2}-a_{3} x_{3}+u_{2}, \\
& \dot{x}_{3}=x_{2}-x_{1}-a_{4} x_{3}+u_{3}, \\
& \dot{x}_{4}=x_{1}+u_{4} .
\end{aligned}
$$

Assume $\dot{x}_{1}=\dot{x}_{2}=\dot{x}_{3}=\dot{x}_{4}=0$ for system (4); then, we obtain the equilibrium points $A=\left\{\left(x_{1}, x_{2}, x_{3}, x_{4}\right) \mid x_{1}=x_{2}=x_{3}=\right.$ $\left.0, x_{4}=c\right\}$. Let

$$
\begin{aligned}
& u_{1}=k_{1} x_{2}+k_{2} x_{3}+k_{3}\left(x_{4}-c\right), \\
& u_{2}=k_{4} x_{1}+k_{5} x_{3}+k_{6}\left(x_{4}-c\right), \\
& u_{3}=k_{7} x_{1}+k_{8} x_{2}+k_{9}\left(x_{4}-c\right), \\
& u_{4}=k_{10} x_{1}+k_{11} x_{2}+k_{12} x_{3},
\end{aligned}
$$

where $k_{i}(i=1,2, \ldots, 12)$ are constants. According to the transformation of following variables, we get

$$
\begin{gathered}
y_{1}=x_{1}, \\
y_{2}=x_{2}, \\
y_{3}=x_{3}, \\
y_{4}=x_{4}-c .
\end{gathered}
$$

Hence

$$
\begin{aligned}
& \dot{y}_{1}=a_{1}\left[y_{3}-\varphi\left(y_{4}\right) y_{1}\right]+k_{1} y_{2}+k_{2} y_{3}+k_{3} y_{4}, \\
& \dot{y}_{2}=a_{2} y_{2}-a_{3} y_{3}+k_{4} y_{1}+k_{5} y_{3}+k_{6} y_{4}, \\
& \dot{y}_{3}=y_{2}-y_{1}-a_{4} y_{3}+k_{7} y_{1}+k_{8} y_{2}+k_{9} y_{4}, \\
& \dot{y}_{4}=y_{1}+k_{10} y_{1}+k_{11} y_{2}+k_{12} y_{3} .
\end{aligned}
$$

Theorem 4. For the equilibrium point $(0,0,0, c)$ of system (17), if the following conditions hold true: $k_{1}+k_{4}=0, k_{2}+k_{7}=1-a_{1}$, $k_{3}+k_{10}=-1, k_{5}+k_{8}=a_{3}-1, k_{6}+k_{11}=0, k_{9}+k_{12}=0$, $a_{1} \varphi\left(y_{4}\right)>0, a_{2}<0$, and $a_{4}>0$, then the controlled system (17) is asymptotically stable.

Proof. Choose a candidate Lyapunov function as follows:

$$
V\left(y_{1}, y_{2}, y_{3}, y_{4}\right)=\frac{1}{2}\left(y_{1}^{2}+y_{2}^{2}+y_{3}^{2}+y_{4}^{2}\right) \text {. }
$$

Then

$$
\begin{aligned}
\dot{V}\left(y_{1}, y_{2}, y_{3}, y_{4}\right)= & y_{1} \dot{y}_{1}+y_{2} \dot{y}_{2}+y_{3} \dot{y}_{3}+y_{4} \dot{y}_{4} \\
= & -a_{1} \varphi\left(y_{4}\right) y_{1}^{2}+k_{1} y_{1} y_{2} \\
& +\left(k_{2}+a_{1}\right) y_{1} y_{3}+k_{3} y_{1} y_{4}+k_{4} y_{1} y_{2} \\
& +a_{2} y_{2}^{2}+\left(k_{5}-a_{3}\right) y_{2} y_{3}+k_{6} y_{2} y_{4} \\
& +\left(k_{7}-1\right) y_{1} y_{3}+\left(k_{8}+1\right) y_{2} y_{3} \\
& -a_{4} y_{3}^{2}+k_{9} y_{3} y_{4}+\left(1+k_{10}\right) y_{1} y_{4} \\
& +k_{11} y_{2} y_{4}+k_{12} y_{3} y_{4} \\
= & -a_{1} \varphi\left(y_{4}\right) y_{1}^{2}+\left(k_{1}+k_{4}\right) y_{1} y_{2} \\
& +\left(k_{2}+a_{1}+k_{7}-1\right) y_{1} y_{3} \\
& +\left(k_{3}+k_{10}+1\right) y_{1} y_{4} \\
& +a_{2} y_{2}^{2}+\left(k_{5}-a_{3}+k_{8}+1\right) y_{2} y_{3} \\
& +\left(k_{6}+k_{11}\right) y_{2} y_{4}-a_{4} y_{3}^{2} \\
& +\left(k_{9}+k_{12}\right) y_{3} y_{4} \\
= & -a_{1} \varphi\left(y_{4}\right) y_{1}^{2}+a_{2} y_{2}^{2}-a_{4} y_{3}^{2} ;
\end{aligned}
$$

if $a_{1} \varphi\left(y_{4}\right)>0, a_{2}<0$, and $a_{4}>0$, then $\dot{V}<0$; system (17) is asymptotically stable. According to (16), the chaotic trajectory of system (17) is driven to the equilibrium point for the controller (15) in theory. 


\section{General Hybrid Projective Dislocated Synchronization of Chaotic Systems}

The section will discuss general hybrid projective dislocated synchronization to achieve synchronization. Consider a drive system

$$
\dot{x}=f(x)
$$

the corresponding response system is

$$
\dot{y}=g(y)+u(x, y)
$$

where $x=\left(x_{1}, x_{2}, \ldots, x_{n}\right)^{T} \in R^{n}$ and $y=\left(y_{1}, y_{2}, \ldots, y_{n}\right)^{T} \in$ $R^{n}$ are two state vectors, $f: R^{n} \rightarrow R^{n}$ and $g: R^{m} \rightarrow R^{m}$ are two continuous functions, and $u(x, y)$ is a controller to be designed later.

Definition 5. If there exists at least a constant $a_{j i} \neq 0(j=$ $1,2, \ldots, m, i=1,2, \ldots, n)$, the condition

$$
\lim _{t \rightarrow \infty}\left\|y_{j}-\sum_{i=1, i \neq j}^{n} a_{j i} x_{i}\right\|=0
$$

can hold true; then the drive system (20) and the corresponding response system (21) are general hybrid projective dislocated synchronization.

In other words, let the error dynamics system of general hybrid projective dislocated synchronization be

$$
\dot{e}=\left(\dot{y}_{1}-\sum_{i=2}^{n} \alpha_{1 i} \dot{x}_{i}, \dot{y}_{2}-\sum_{i=1, i \neq 2}^{n} \alpha_{2 i} \dot{x}_{i}, \ldots, \dot{y}_{m}-\sum_{i=1, i \neq m}^{n} \alpha_{m i} \dot{x}_{i}\right)^{T} ;
$$

then there exist a suitable feedback controller $u(x, y) \in R^{m}$ and a constant $\alpha_{s i}$, so

$$
\lim _{t \rightarrow \infty}\|e(t)\|=0
$$

In the following section, we will give a principle to find a suitable feedback controller $u(x, y)$ such that the two chaotic systems are general hybrid projective dislocated synchronization. Lyapunov function is chosen as follows:

$$
V=\frac{1}{2} e^{T} P e
$$

where $P$ is a positive definite constant matrix. The time derivative of $V$ along the trajectories of (25) is

$$
\dot{V}=\frac{1}{2}\left(\dot{e}^{T} P e+e^{T} P \dot{e}\right)
$$

If the feedback controller $u(x, y)$ is chosen for $\dot{V}<0$, according to the Lyapunov stability theorem, the drive system (20) and the corresponding response system (21) are general hybrid projective dislocated synchronization.
4.1. General Hybrid Projective Dislocated Synchronization of Memristor Chaotic Oscillator Systems. General hybrid projective dislocated synchronization will be discussed for memristor chaotic oscillator systems.

4.1.1. Equality of the Dimensions for the Drive System and the Response System. In this section, we take into account the equality of the dimensions of the drive and response systems. The memristor chaotic oscillator system is given as the drive system

$$
\begin{aligned}
& \dot{x}_{1}=a_{1}\left[x_{3}-\varphi\left(x_{4}\right) x_{1}\right], \\
& \dot{x}_{2}=a_{2} x_{2}-a_{3} x_{3}, \\
& \dot{x}_{3}=x_{2}-x_{1}-a_{4} x_{3}, \\
& \dot{x}_{4}=x_{1} ;
\end{aligned}
$$

the identical memristor chaotic oscillator system is written as the response system

$$
\begin{aligned}
& \dot{y}_{1}=a_{1}\left[y_{3}-\varphi\left(y_{4}\right) y_{1}\right]+u_{1}, \\
& \dot{y}_{2}=a_{2} y_{2}-a_{3} y_{3}+u_{2}, \\
& \dot{y}_{3}=y_{2}-y_{1}-a_{4} y_{3}+u_{3}, \\
& \dot{y}_{4}=y_{1}+u_{4} .
\end{aligned}
$$

Let

$$
\begin{aligned}
& e_{1}=y_{1}+d_{1} x_{2}+d_{2} x_{3}+d_{3} x_{4} \text {, } \\
& e_{2}=y_{2}+d_{4} x_{1}+d_{5} x_{3}+d_{6} x_{4}, \\
& e_{3}=y_{3}+d_{7} x_{1}+d_{8} x_{2}+d_{9} x_{4} \text {, } \\
& e_{4}=y_{4}+d_{10} x_{1}+d_{11} x_{2}+d_{12} x_{3} \text {, } \\
& u_{1}=-a_{1}\left[y_{3}-\varphi\left(y_{4}\right) y_{1}\right]-d_{1}\left(a_{2} x_{2}-a_{3} x_{3}\right) \\
& -d_{2}\left(x_{2}-x_{1}-a_{4} x_{3}\right)-d_{3} x_{1} \\
& -a_{1}\left(y_{1}+d_{1} x_{2}+d_{2} x_{3}+d_{3} x_{4}\right) \text {, } \\
& u_{2}=a_{3} y_{3}-a_{2} y_{2}-a_{1} d_{4}\left[x_{3}-\varphi\left(x_{4}\right) x_{1}\right] \\
& -d_{5}\left(x_{2}-x_{1}-a_{4} x_{3}\right)-d_{6} x_{1} \\
& -a_{2}\left(y_{2}+d_{4} x_{1}+d_{5} x_{3}+d_{6} x_{4}\right) \text {, } \\
& u_{3}=-\left(y_{2}-y_{1}-a_{4} y_{3}\right) \\
& -d_{7} a_{1}\left[x_{3}-\varphi\left(x_{4}\right) x_{1}\right] \\
& -d_{8}\left(a_{2} x_{2}-a_{3} x_{3}\right)-d_{9} x_{1} \\
& -a_{3}\left(y_{3}+d_{7} x_{1}+d_{8} x_{2}+d_{9} x_{4}\right) \text {, } \\
& u_{4}=-y_{1}-a_{1} d_{10}\left[x_{3}-\varphi\left(x_{4}\right) x_{1}\right] \\
& -d_{11}\left(a_{2} x_{2}-a_{3} x_{3}\right) \\
& -d_{12}\left(x_{2}-x_{1}-a_{4} x_{3}\right) \\
& -a_{4}\left(y_{4}+d_{10} d_{1}+d_{11} x_{2}+d_{12} x_{3}\right) \text {, }
\end{aligned}
$$

where $d_{i}(i=1,2, \ldots, 12)$ are constants. 
Theorem 6. If the conditions $a_{1}>0, a_{2}>0, a_{3}>0$, and $a_{4}>0$ hold true, then systems (27) and (28) can realize general hybrid projective dislocated synchronization under the adaptive control law (30).

Proof. It is easy to see from (27) and (28) that the error dynamics system can be obtained as follows:

$$
\begin{aligned}
\dot{e}_{1}= & a_{1}\left[y_{3}-\varphi\left(y_{4}\right) y_{1}\right]+u_{1}+d_{1}\left(a_{2} x_{2}-a_{3} x_{3}\right) \\
& +d_{2}\left(x_{2}-x_{1}-a_{4} x_{3}\right)+d_{3} x_{1}, \\
\dot{e}_{2}= & a_{2} y_{2}-a_{3} y_{3}+u_{2}+d_{4}\left(x_{3}-\varphi\left(x_{4}\right) x_{1}\right) \\
& +d_{5}\left(x_{2}-x_{1}-a_{4} x_{3}\right)+d_{6} x_{1}, \\
\dot{e}_{3}= & y_{2}-y_{1}-a_{4} y_{3}+u_{3}+d_{7} a_{1}\left[x_{3}-\varphi\left(x_{4}\right) x_{1}\right] \\
& +d_{8}\left(a_{2} x_{2}-a_{3} x_{3}\right)+d_{9} x_{1}, \\
\dot{e}_{4}= & y_{1}+u_{4}+d_{10} a_{1}\left[x_{3}-\varphi\left(x_{4}\right) x_{1}\right] \\
& +d_{11}\left(a_{2} x_{2}-a_{3} x_{3}\right)+d_{12}\left(x_{2}-x_{1}-a_{4} x_{3}\right) .
\end{aligned}
$$

Choose a candidate Lyapunov function

$$
V=\frac{1}{2}\left(e_{1}^{2}+e_{2}^{2}+e_{3}^{2}+e_{4}^{2}\right) \text {. }
$$

Then

$$
\begin{aligned}
\dot{V}\left(e_{1}, e_{2}, e_{3}, e_{4}\right) & =e_{1} \dot{e}_{1}+e_{2} \dot{e}_{2}+e_{3} \dot{e}_{3}+e_{4} \dot{e}_{4} \\
& =-a_{1} e_{1}^{2}-a_{2} e_{2}^{2}-a_{3} e_{3}^{2}-a_{4} e_{4}^{2} \\
& =-e^{T} P e,
\end{aligned}
$$

where $e=\left[e_{1}, e_{2}, e_{3}, e_{4}\right]^{T}$,

$$
P=\left[\begin{array}{cccc}
a_{1} & 0 & 0 & 0 \\
0 & a_{2} & 0 & 0 \\
0 & 0 & a_{3} & 0 \\
0 & 0 & 0 & a_{4}
\end{array}\right] .
$$

According to Lyapunov theorem, $a_{1}>0, a_{2}>0, a_{3}>0$, and $a_{4}>0 ; P$ is a positive definite constant matrix; this leads to

$$
\lim _{t \rightarrow \infty}\|e(t)\|=0 .
$$

Therefore, the corresponding response system (28) can realize general hybrid projective dislocated synchronization with the drive system (27) for the controller (30).

4.1.2. Inequality of the Dimensions for the Drive System and the Response System. Here, there are different dimensions for the drive system and the corresponding response system. The general hybrid projective dislocated synchronization between the memristor chaotic oscillator system (27) and the chaotic system [25] will be discussed. The chaotic system is given as follows:

$$
\begin{aligned}
& \dot{x}_{1}=b_{1}\left(x_{2}-x_{1}\right), \\
& \dot{x}_{2}=b_{2} x_{1}-x_{1} x_{3}, \\
& \dot{x}_{3}=x_{1} x_{2}+b_{3} x_{3} .
\end{aligned}
$$

Case (a) $(n<m)$. The corresponding response system is written as follows:

$$
\begin{aligned}
& \dot{y}_{1}=b_{1}\left(y_{2}-y_{1}\right)+u_{1}, \\
& \dot{y}_{2}=b_{2} y_{1}-y_{1} y_{3}+u_{2}, \\
& \dot{y}_{3}=y_{1} y_{2}+b_{3} y_{3}+u_{3} .
\end{aligned}
$$

Assume

$$
\begin{aligned}
& e_{1}=y_{1}+h_{1} x_{2}+h_{2} x_{3}+h_{3} x_{4}, \\
& e_{2}=y_{2}+h_{4} x_{1}+h_{5} x_{3}+h_{6} x_{4}, \\
& e_{3}=y_{3}+h_{7} x_{1}+h_{8} x_{2}+h_{9} x_{4}, \\
u_{1}= & -b_{1}\left(y_{2}-y_{1}\right)-h_{1}\left(a_{2} x_{2}-a_{3} x_{3}\right) \\
& -h_{2}\left(x_{2}-x_{1}-a_{4} x_{3}\right)-h_{3} x_{1} \\
& -b_{1}\left(y_{1}+h_{1} x_{2}+h_{2} x_{3}+h_{3} x_{4}\right), \\
u_{2}= & y_{1} y_{3}-b_{2} y_{1}-h_{4} a_{1}\left[x_{3}-\varphi\left(x_{4}\right) x_{1}\right] \\
& -h_{5}\left(x_{2}-x_{1}-a_{4} x_{3}\right)-h_{6} x_{1} \\
& -b_{2}\left(y_{2}+h_{4} x_{1}+h_{5} x_{3}+h_{6} x_{4}\right), \\
u_{3}= & -y_{1} y_{2}-b_{3} y_{3}-h_{7} a_{1}\left[x_{3}-\varphi\left(x_{4}\right) x_{1}\right] \\
& -h_{8}\left(a_{2} x_{2}-a_{3} x_{3}\right)-h_{9} x_{1} \\
& -b_{3}\left(y_{3}+h_{7} x_{1}+h_{8} x_{2}+h_{9} x_{4}\right),
\end{aligned}
$$

where $h_{i}(i=1,2, \ldots, 9)$ are constants.

Theorem 7. If the conditions $b_{1}>0, b_{2}>0$, and $b_{3}>$ 0 hold true, then systems (27) and (37) can realize general hybrid projective dislocated synchronization under the adaptive control law (39).

Proof. It is easy to see from (27) and (37) that the error dynamics system can be obtained as follows:

$$
\begin{aligned}
\dot{e}_{1}= & b_{1}\left(y_{2}-y_{1}\right)+u_{1}+h_{1}\left(a_{2} x_{2}-a_{3} x_{3}\right) \\
& +h_{2}\left(x_{2}-x_{1}-a_{4} x_{3}\right)+h_{3} x_{1}, \\
\dot{e}_{2}= & b_{2} y_{1}-y_{1} y_{3}+u_{2}+h_{4} a_{1}\left[x_{3}-\varphi\left(x_{4}\right) x_{1}\right] \\
& +h_{5}\left(x_{2}-x_{1}-a_{4} x_{3}\right)+h_{6} x_{1}, \\
\dot{e}_{3}= & y_{1} y_{2}+b_{3} y_{3}+u_{3}+h_{7} a_{1}\left[x_{3}-\varphi\left(x_{4}\right) x_{1}\right] \\
& +h_{8}\left(a_{2} x_{2}-a_{3} x_{3}\right)+h_{9} x_{1} .
\end{aligned}
$$

Choose a candidate Lyapunov function as follows:

$$
V\left(e_{1}, e_{2}, e_{3}\right)=\frac{1}{2}\left(e_{1}^{2}+e_{2}^{2}+e_{3}^{2}\right) .
$$


Then

$$
\begin{aligned}
\dot{V}\left(e_{1}, e_{2}, e_{3}\right) & =e_{1} \dot{e}_{1}+e_{2} \dot{e}_{2}+e_{3} \dot{e}_{3} \\
& =-b_{1} e_{1}^{2}-b_{2} e_{2}^{2}-b_{3} e_{3}^{2} \\
& =-e^{T} P e,
\end{aligned}
$$

where $e=\left[e_{1}, e_{2}, e_{3}\right]^{T}$,

$$
P=\left[\begin{array}{ccc}
b_{1} & 0 & 0 \\
0 & b_{2} & 0 \\
0 & 0 & b_{3}
\end{array}\right]
$$

According to Lyapunov theorem, $b_{1}>0, b_{2}>0$, and $b_{3}>$ $0 ; P$ is a positive definite constant matrix; this leads to

$$
\lim _{t \rightarrow \infty}\|e(t)\|=0
$$

Hence the drive system (27) and the corresponding response system (37) are general hybrid projective dislocated synchronization for the controller (39).

Case (b) $(n>m)$. System (36) is the drive system. The memristor chaotic oscillator system is the corresponding response system:

$$
\begin{aligned}
& \dot{y}_{1}=a_{1}\left[y_{3}-\varphi(w) y_{1}\right]+u_{1}, \\
& \dot{y}_{2}=a_{2} y_{2}-a_{3} y_{3}+u_{2}, \\
& \dot{y}_{3}=y_{2}-y_{1}-a_{4} y_{3}+u_{3}, \\
& \dot{y}_{4}=y_{1}+u_{4} .
\end{aligned}
$$

Assume

$$
\begin{gathered}
e_{1}=y_{1}+k_{1} x_{2}+k_{2} x_{3}, \\
e_{2}=y_{2}+k_{3} x_{1}+k_{4} x_{3}, \\
e_{3}=y_{3}+k_{5} x_{1}+k_{6} x_{2}, \\
e_{4}=y_{4}+k_{7} x_{1}+k_{8} x_{2}+k_{9} x_{3}, \\
u_{1}=-a_{1}\left[y_{3}-\varphi(w) y_{1}\right]-k_{1}\left(b_{2} x_{1}-x_{1} x_{3}\right) \\
-k_{2}\left(x_{1} x_{2}+b_{3} x_{3}\right)-a_{1}\left(y_{1}+k_{1} x_{2}+k_{2} x_{3}\right), \\
u_{2}=a_{3} y_{3}-a_{2} y_{2}-b_{1} k_{3}\left(x_{2}-x_{1}\right) \\
-k_{4}\left(x_{1} x_{2}+b_{3} x_{3}\right)-a_{2}\left(y_{2}+k_{3} x_{1}+k_{4} x_{3}\right), \\
u_{3}=-\left(y_{2}-y_{1}-d_{4} y_{3}\right)-b_{1} k_{5}\left(x_{2}-x_{1}\right) \\
-k_{6}\left(b_{2} x_{1}-x_{1} x_{3}\right)-a_{3}\left(y_{3}+k_{5} x_{1}+k_{6} x_{2}\right), \\
u_{4}=-y_{1}-b_{1} k_{7}\left(x_{2}-x_{1}\right) \\
-k_{8}\left(b_{2} x_{1}-x_{1} x_{3}\right)-k_{9}\left(x_{1} x_{2}+b_{3} x_{3}\right) \\
-a_{4}\left(y_{4}+k_{7} x_{1}+k_{8} x_{2}+k_{9} x_{3}\right),
\end{gathered}
$$

where $k_{i}(i=1,2, \ldots, 9)$ are constants.
Theorem 8. If the conditions $a_{1}>0, a_{2}>0, a_{3}>0$, and $a_{4}>0$ hold true, then systems (27) and (45) can realize general hybrid projective dislocated synchronization under the adaptive control law (47).

Proof. It is easy to see from (27) and (45) that the error dynamics system can be obtained as follows:

$$
\begin{aligned}
\dot{e}_{1}= & a_{1}\left[y_{3}-\varphi(w) y_{1}\right]+u_{1} \\
& +k_{1}\left(b_{2} x_{1}-x_{1} x_{3}\right)+k_{2}\left(x_{1} x_{2}+b_{3} x_{3}\right), \\
\dot{e}_{2}= & a_{2} y_{2}-a_{3} y_{3}+u_{2} \\
& +b_{1} k_{3}\left(x_{2}-x_{1}\right)+k_{4}\left(x_{1} x_{2}+b_{3} x_{3}\right), \\
\dot{e}_{3}= & y_{2}-y_{1}-a_{4} y_{3}+u_{3} \\
& +b_{1} k_{5}\left(x_{2}-x_{1}\right)+k_{6}\left(b_{2} x_{1}-x_{1} x_{3}\right), \\
\dot{e}_{4}= & y_{1}+u_{4}+b_{1} k_{7}\left(x_{2}-x_{1}\right) \\
& +k_{8}\left(b_{2} x_{1}-x_{1} x_{3}\right)+k_{9}\left(x_{1} x_{2}+b_{3} x_{3}\right) .
\end{aligned}
$$

Choose a candidate Lyapunov function as follows:

$$
V\left(e_{1}, e_{2}, e_{3}, e_{4}\right)=\frac{1}{2}\left(e_{1}^{2}+e_{2}^{2}+e_{3}^{2}+e_{4}^{2}\right) \text {. }
$$

Then

$$
\begin{aligned}
\dot{V}\left(e_{1}, e_{2}, e_{3}, e_{4}\right) & =e_{1} \dot{e}_{1}+e_{2} \dot{e}_{2}+e_{3} \dot{e}_{3}+e_{4} \dot{e}_{4} \\
& =-a_{1} e_{1}^{2}-a_{2} e_{2}^{2}-a_{3} e_{3}^{2}-a_{4} e_{4}^{2} \\
& =-e^{T} P e,
\end{aligned}
$$

where $e=\left[e_{1}, e_{2}, e_{3}, e_{4}\right]^{T}$,

$$
P=\left[\begin{array}{cccc}
a_{1} & 0 & 0 & 0 \\
0 & a_{2} & 0 & 0 \\
0 & 0 & a_{3} & 0 \\
0 & 0 & 0 & a_{4}
\end{array}\right]
$$

According to the Lyapunov theorem, $a_{1}>0, a_{2}>0, a_{3}>$ 0 , and $a_{4}>0 ; P$ is a positive definite constant matrix; this leads to

$$
\lim _{t \rightarrow \infty}\|e(t)\|=0
$$

Hence the drive system (27) and the corresponding response system (45) can realize general hybrid projective dislocated synchronization for the controller (47) (see Figure 7).

\section{Illustrative Examples}

Example 1. Consider the control chaos with hybrid dislocated control method. The parameters of system (4) are chosen as $a_{1}=5.1, a_{2}=-0.5, a_{3}=1, a_{4}=0.12, k_{1}=1$, $k_{2}=-1, k_{3}=-1, k_{4}=-1, k_{5}=1, k_{6}=1, k_{7}=-3.1$, $k_{8}=-1, k_{9}=1, k_{10}=0, k_{11}=-1$, and $k_{12}=-1$, and the 

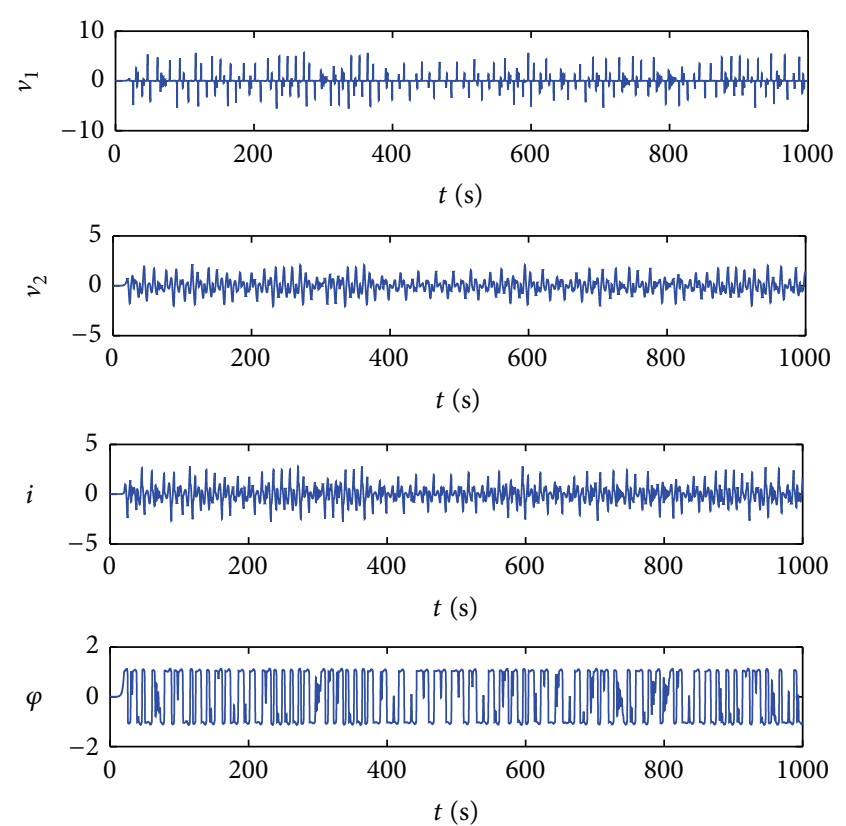

FIGURE 7: Time-domain waveforms.

initial condition is $\left(10^{-4}, 0,0,0\right)$. According to Theorem 4 , the system is successfully controlled to the equilibrium point.

Simulation results of $y_{1}, y_{2}, y_{3}$, and $y_{4}$ are depicted in Figures 8 and 9. The system is controlled to the equilibrium point $(0,0,0,1)$ in Figure 8 . The system is controlled to the equilibrium point $(0,0,0,-1)$ in Figure 9 . It is easy to see that $y_{1} \rightarrow 0, y_{2} \rightarrow 0, y_{3} \rightarrow 0$, and $y_{4} \rightarrow 0$; system (4) is asymptotically stable. System (4) is successfully controlled to the equilibrium points.

Example 2. Consider the drive system (27) and the corresponding response system (28); the initial conditions are $\left(10^{-8}, 2 * 10^{-8}, 3 * 10^{-2}, 4 * 10^{-8}\right)$ and $\left(5 * 10^{-8}, 6 * 10^{-8}, 7 *\right.$ $\left.10^{-2}, 8 * 10^{-8}\right)$; parameters are $d_{1}=1, d_{2}=-2, d_{3}=-1$, $d_{4}=1, d_{5}=-2, d_{6}=-1, d_{7}=1, d_{8}=-2, d_{9}=-1, d_{10}=1$, $d_{11}=-2, d_{12}=-1, a_{1}=5.1 * 10^{-8}, a_{2}=1, a_{3}=0.69, a_{4}=$ 0.12. $a_{1}>0, a_{2}>0, a_{3}>0$, and $a_{4}>0$, and $P$ is a positive definite constant matrix. According to Theorem 6, the drive system (27) and the corresponding response system (28) can realize general hybrid projective dislocated synchronization for the controller (30).

The iterations have been done 100 times. Simulation results of $e_{1}, e_{2}, e_{3}$, and $e_{4}$ are depicted in Figure 10. It is easy to see that $e_{1} \rightarrow 0, e_{2} \rightarrow 0, e_{3} \rightarrow 0$, and $e_{4} \rightarrow 0$. Thus, the drive system (27) and the corresponding response system (28) can realize general hybrid projective dislocated synchronization for the controller (30).

Example 3. Consider the drive system (27) and the corresponding response system (37); the initial conditions are $\left(10^{-8}, 2 * 10^{-8}, 3 * 10^{-2}\right)$ and $\left(5 * 10^{-8}, 6 * 10^{-8}, 7 * 10^{-2}, 8 *\right.$ $\left.10^{-8}\right)$; parameters are $h_{1}=1, h_{2}=-2, h_{3}=-1, h_{4}=1$, $h_{5}=-2, h_{6}=-1, h_{7}=1, h_{8}=-2, h_{9}=-1, b_{1}=5.1 * 10^{-8}$, $b_{2}=2, b_{3}=0.69, a_{1}=5.1 * 10^{-8}, a_{2}=0.69, a_{3}=1$,
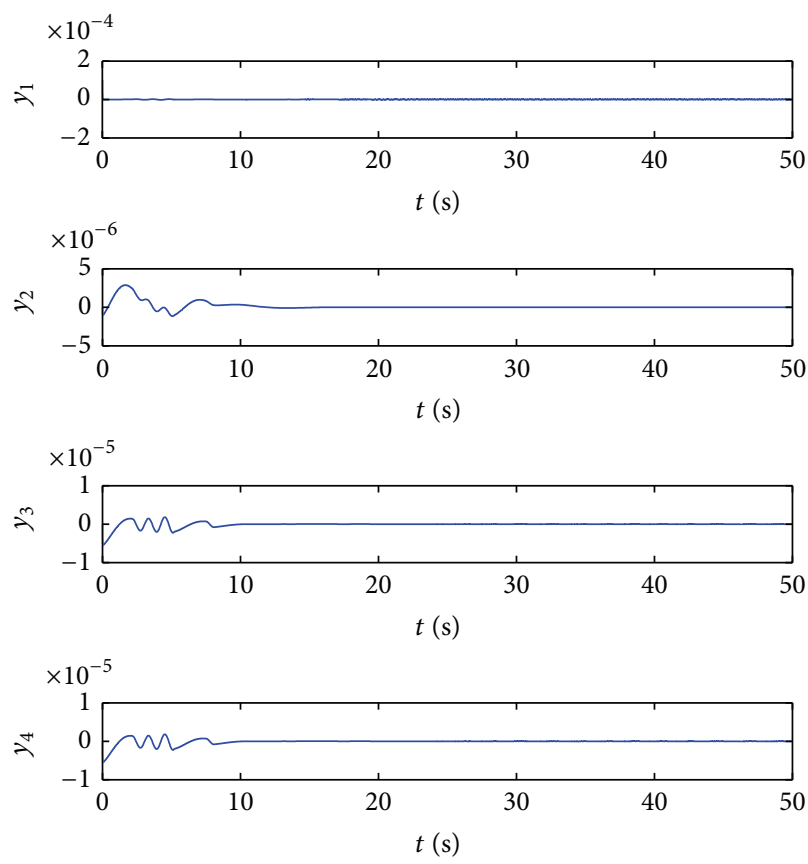

FIGURE 8: Control to the equilibrium point $(0,0,0,1)$.
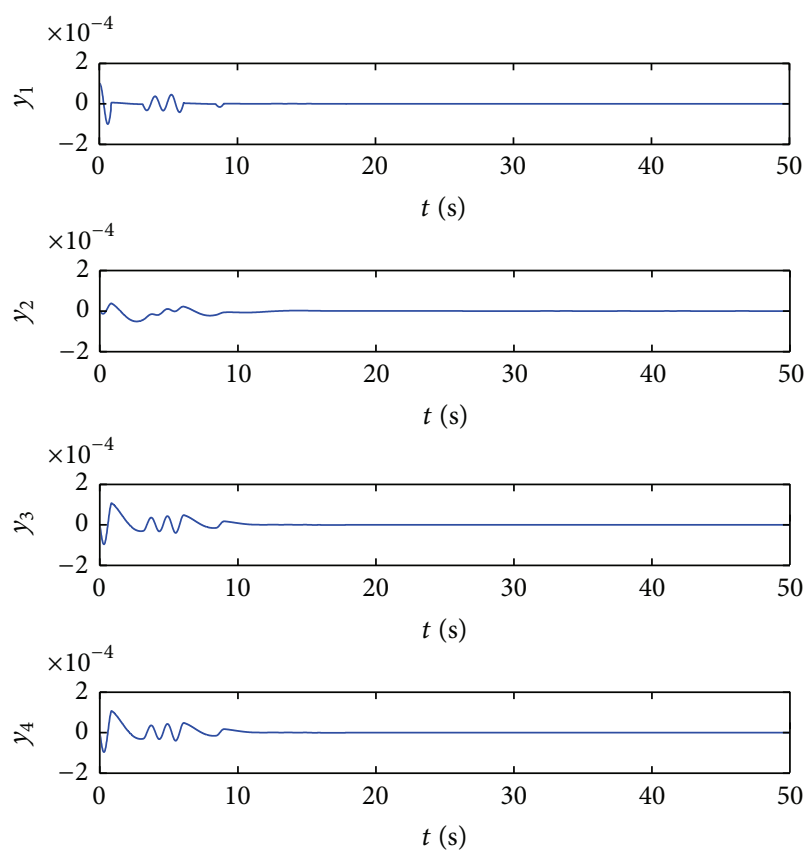

FIgURE 9: Control to the equilibrium point $(0,0,0,-1)$.

$a_{4}=0.12 \cdot b_{1}>0, b_{2}>0$, and $b_{3}>0$, and $P$ is a positive definite constant matrix. According to Theorem 7, the drive system (27) and the corresponding response system (37) can realize general hybrid projective dislocated synchronization for the controller (39).

The iterations have been done 200 times. Simulation results of $e_{1}, e_{2}$, and $e_{3}$ are depicted in Figure 11. It is easy to see that $e_{1} \rightarrow 0, e_{2} \rightarrow 0$, and $e_{3} \rightarrow 0$. Thus, the drive system 

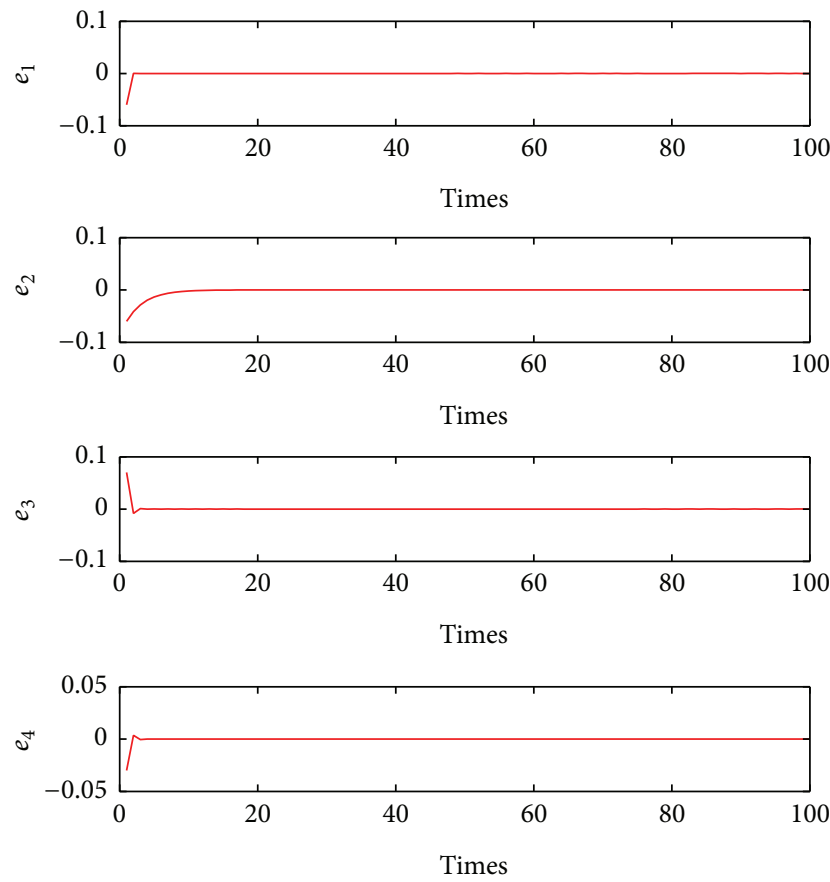

FIgURE 10: Synchronization errors $e_{1}, e_{2}, e_{3}, e_{4}$ of $m=n$.
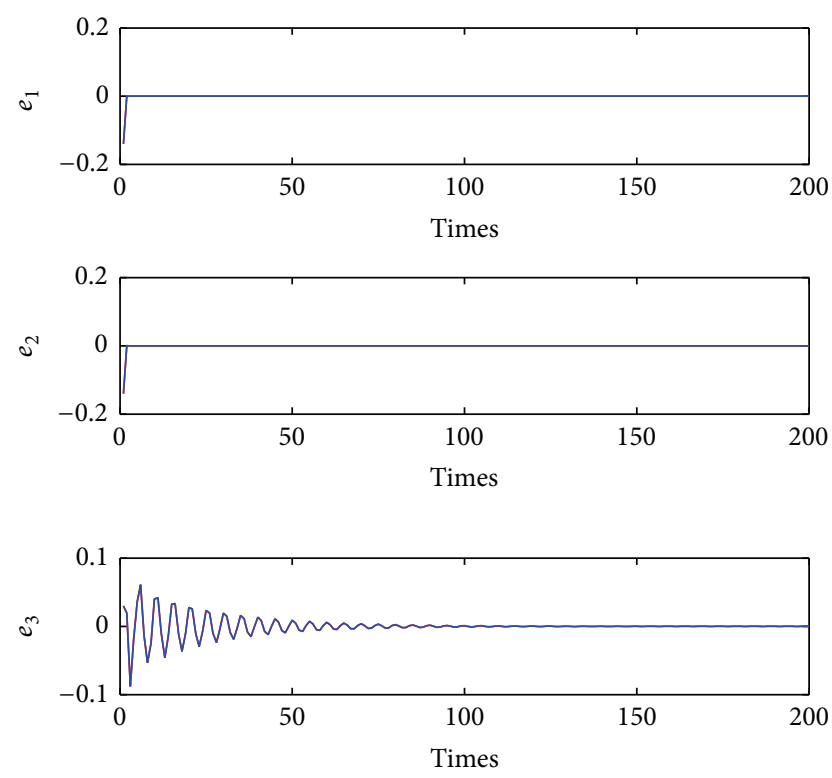

FIGURE 11: Synchronization errors $e_{1}, e_{2}, e_{3}$ of $n<m$.

(27) and the corresponding response system (37) can realize general hybrid projective dislocated synchronization for the controller (39).

Example 4. Consider the drive system (27) and the corresponding response system (45); the initial conditions are $\left(10^{-8}, 2 * 10^{-8}, 3 * 10^{-2}\right)$ and $\left(5 * 10^{-8}, 6 * 10^{-8}, 7 * 10^{-2}, 8 *\right.$ $\left.10^{-8}\right)$; parameters are $k_{1}=1, k_{2}=-1, k_{3}=1, k_{4}=-1, k_{5}=1$, $k_{6}=-1, k_{7}=1, k_{8}=-1, k_{9}=1, a_{1}=5.1 * 10^{-8}, a_{2}=0.69$, $a_{3}=1, a_{4}=0.12, b_{1}=5.1 * 10^{-8}, b_{2}=2, b_{3}=0.69 . a_{1}>0$,
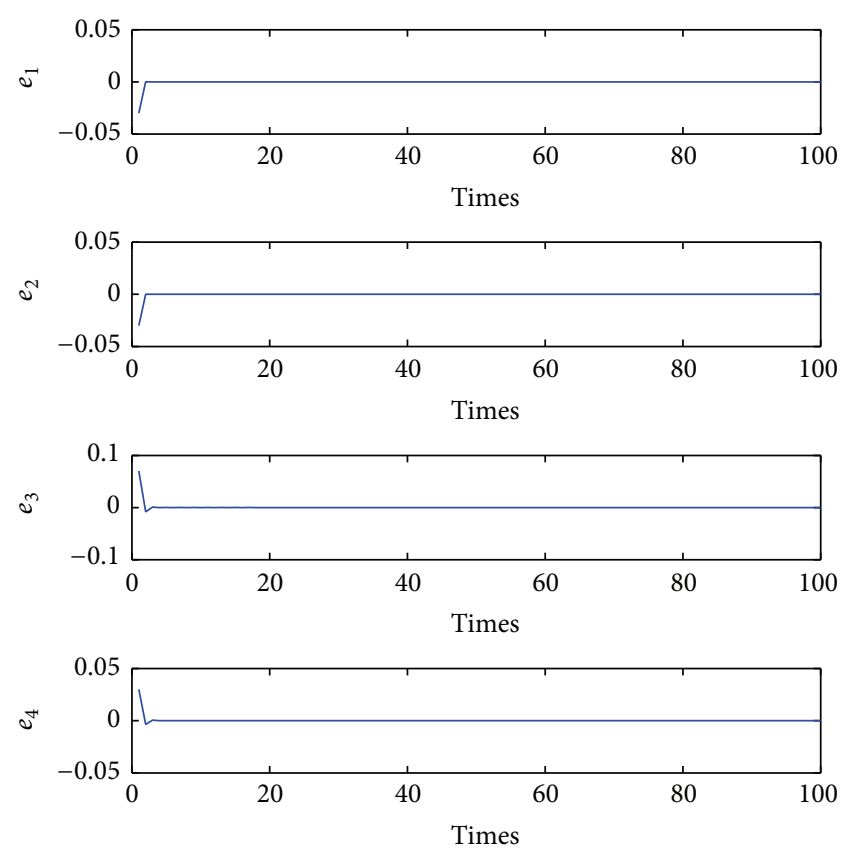

FIGURE 12: Synchronization errors $e_{1}, e_{2}, e_{3}, e_{4}$ of $n>m$.

$a_{2}>0, a_{3}>0$, and $a_{4}>0$, and $P$ is a positive definite constant matrix. According to Theorem 8, the drive system (27) and the corresponding response system (45) can realize general hybrid projective dislocated synchronization for the controller (47).

The iterations have been done 100 times. Simulation results of $e_{1}, e_{2}, e_{3}$, and $e_{4}$ are depicted in Figure 12. It is easy to see that $e_{1} \rightarrow 0, e_{2} \rightarrow 0, e_{3} \rightarrow 0$, and $e_{4} \rightarrow 0$. Thus, the drive system (27) and the corresponding response system (45) can realize general hybrid projective dislocated synchronization for the controller (47).

\section{Conclusion}

Some important dynamical properties have been gained for the memristor chaotic oscillator system. Based on these properties, we realize hybrid dislocated control method for stabilizing chaos to unstable equilibrium. There have been more significant advantages in controlling chaos in the memristor chaotic oscillator system. We need not consider the position of controller in our method. Particularly, hybrid dislocated control method can control chaos to all the unstable equilibrium points.

In addition, based on the Lyapunov stability theorem, general hybrid projective dislocated synchronization has been investigated for the memristor chaotic oscillator system. The drive and response systems discussed in this paper can be the same as the memristor chaotic oscillator systems. Finally, the memristor chaotic oscillator system and the chaotic system have realized general hybrid projective dislocated synchronization for the different dimensions. Numerical illustrative simulation examples are given to show the effectiveness of these methods and the accuracy of the statements 
proved. With the rapid development of science and technology and combination of multidisciplinary science, hybrid dislocated control and general hybrid projective dislocated synchronization for memristor chaotic oscillator system have a very bright future in various practical application fields.

\section{Conflict of Interests}

The authors declare that there is no conflict of interests regarding the publication of this paper.

\section{Acknowledgments}

The work is supported by the State Key Program of the National Natural Science Foundation of China (Grant no. 61134012), the National Natural Science Foundation of China (Grants nos. 11271146 and 61374150), the Specialized Research Fund for the Doctoral Program of Higher Education of China (Grant no. 20130142130012), and the Science and Technology Program of Wuhan (Grant no. 20130105010117).

\section{References}

[1] L. O. Chua, "Memristor-the missing circuit element," IEEE Transactions on Circuit Theory, vol. 18, no. 5, pp. 507-519, 1971.

[2] D. B. Strukov, G. S. Snider, D. R. Stewart, and R. S. Williams, "The missing memristor found," Nature, vol. 453, no. 7191, pp. 80-83, 2008.

[3] E. Ott, C. Grebogi, and J. A. Yorke, "Controlling chaos," Physical Review Letters, vol. 64, no. 11, pp. 1196-1199, 1990.

[4] M. T. Yassen, "Controlling chaos and synchronization for new chaotic system using linear feedback control," Chaos, Solitons and Fractals, vol. 26, no. 3, pp. 913-920, 2005.

[5] H. N. Agiza and M. T. Yassen, "Synchronization of Rossler and Chen chaotic dynamical systems using active control," Physics Letters A, vol. 278, no. 4, pp. 191-197, 2001.

[6] Y. Yu and H. X. Li, "Adaptive hybrid projective synchronization of uncertain chaotic systems based on backstepping design," Nonlinear Analysis: Real World Applications, vol. 12, no. 1, pp. 388-393, 2011.

[7] X. Wang and Y. Wang, "Adaptive control for synchronization of a four-dimensional chaotic system via a single variable," Nonlinear Dynamics, vol. 65, no. 3, pp. 311-316, 2011.

[8] J. Sun, Y. Shen, G. Zhang, C. Xu, and G. Cui, "Combinationcombination synchronization among four identical or different chaotic systems," Nonlinear Dynamics, vol. 73, no. 3, pp. 12111222, 2013.

[9] J. Sun, Y. Shen, Q. Yin, and C. Xu, "Compound synchronization of four memristor chaotic oscillator systems and secure communication," Chaos, vol. 23, no. 1, Article ID 013140, 2013.

[10] J.-W. Sun, Y. Shen, G.-D. Zhang, Y.-F. Wang, and G.-Z. Cui, "General hybrid projective complete dislocated synchronization with non-derivative and derivative coupling based on parameter identification in several chaotic and hyperchaotic systems," Chinese Physics B, vol. 22, no. 4, Article ID 040508, 2013.

[11] J. Sun, Q. Yin, and Y. Shen, "Compound synchronization for four chaotic systems of integer order and fractional order," Europhysics Letters, vol. 106, no. 4, Article ID 40005, 2014.
[12] J. Sun, Y. Shen, and X. Zhang, "Modified projective and modified function projective synchronization of a class of real nonlinear systems and a class of complex nonlinear systems," Nonlinear Dynamics, 2014.

[13] J. Sun, Y. Shen, X. Wang, and J. Chen, "Finite-time combinationcombination synchronization of four different chaotic systems with unknown parameters via sliding mode control," Nonlinear Dynamics, vol. 76, no. 1, pp. 383-397, 2014.

[14] J. Sun, Y. Shen, and G. Zhang, “Transmission projective synchronization of multi-systems with non-delayed and delayed coupling via impulsive control," Chaos, vol. 22, no. 4, Article ID 043107, 2012.

[15] D. Sun, "Position synchronization of multiple motion axes with adaptive coupling control," Automatica, vol. 39, no. 6, pp. 9971005, 2003.

[16] B. C. Bao, Z. Liu, and J. P. Xu, "Transient chaos in smooth memristor oscillator," Chinese Physics B, vol. 19, no. 3, Article ID 030510, 2010.

[17] B.-C. Bao, J.-P. Xu, and Z. Liu, "Initial state dependent dynamical behaviors in a memristor based chaotic circuit," Chinese Physics Letters, vol. 27, no. 7, Article ID 070504, pp. 51-53, 2010.

[18] B. Bao, Z. Ma, J. Xu, Z. Liu, and Q. Xu, "A simple memristor chaotic circuit with complex dynamics," International Journal of Bifurcation and Chaos, vol. 21, no. 9, pp. 2629-2645, 2011.

[19] B.-C. Bao, J.-P. Xu, G.-H. Zhou, Z.-H. Ma, and L. Zou, "Chaotic memristive circuit: equivalent circuit realization and dynamical analysis," Chinese Physics B, vol. 20, Article ID 120502, 2011.

[20] J. Sun and Y. Shen, "Quasi-ideal memory system," IEEE Transactions on Cybernetics, no. 99, 2014.

[21] Q. Zhong, J. Bao, Y. Yu, and X. Liao, "Impulsive control for T-S fuzzy model-based chaotic systems," Mathematics and Computers in Simulation, vol. 79, no. 3, pp. 409-415, 2008.

[22] S. Wen, Z. Zeng, and T. Huang, "Adaptive synchronization of memristor-based Chua's circuits," Physics Letters A, vol. 376, no. 44, pp. 2775-2780, 2012.

[23] Y. Song, Y. Shen, and Y. Chang, "Chaos control of a memristorbased Chua's oscillator via backstepping method," in Proceedings of the International Conference on Information Science and Technology (ICIST '11), pp. 1081-1084, Nanjing, China, March 2011.

[24] H. H. Iu, D. S. Yu, A. L. Fitch, V. Sreeram, and H. Chen, "Controlling chaos in a memristor based circuit using a twinT notch filter," IEEE Transactions on Circuits and Systems. I. Regular Papers, vol. 58, no. 6, pp. 1337-1344, 2011.

[25] Y. Xu, W. Zhou, and J. Fang, "Hybrid dislocated control and general hybrid projective dislocated synchronization for the modified Lü chaotic system," Chaos, Solitons and Fractals, vol. 42, no. 3, pp. 1305-1315, 2009. 


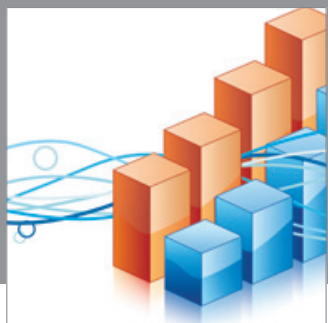

Advances in

Operations Research

mansans

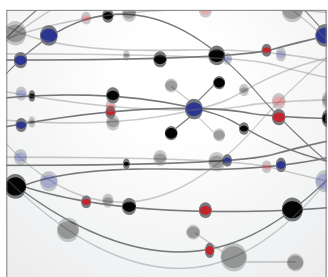

The Scientific World Journal
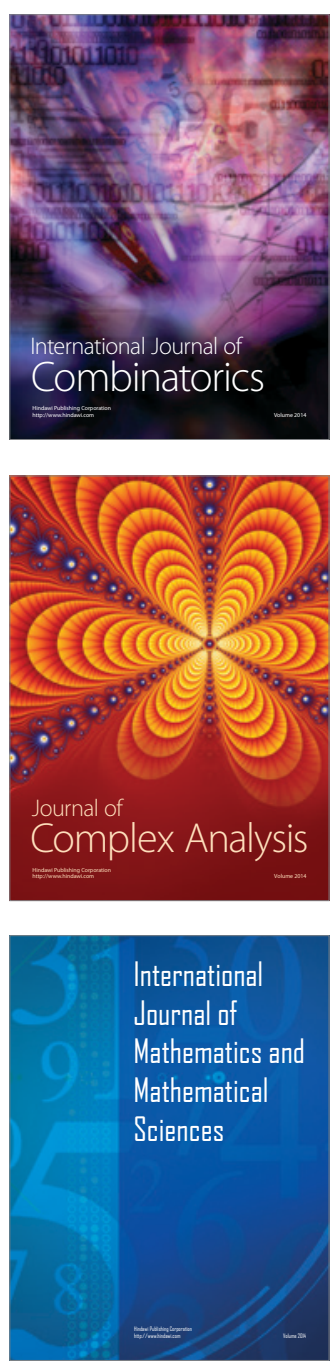
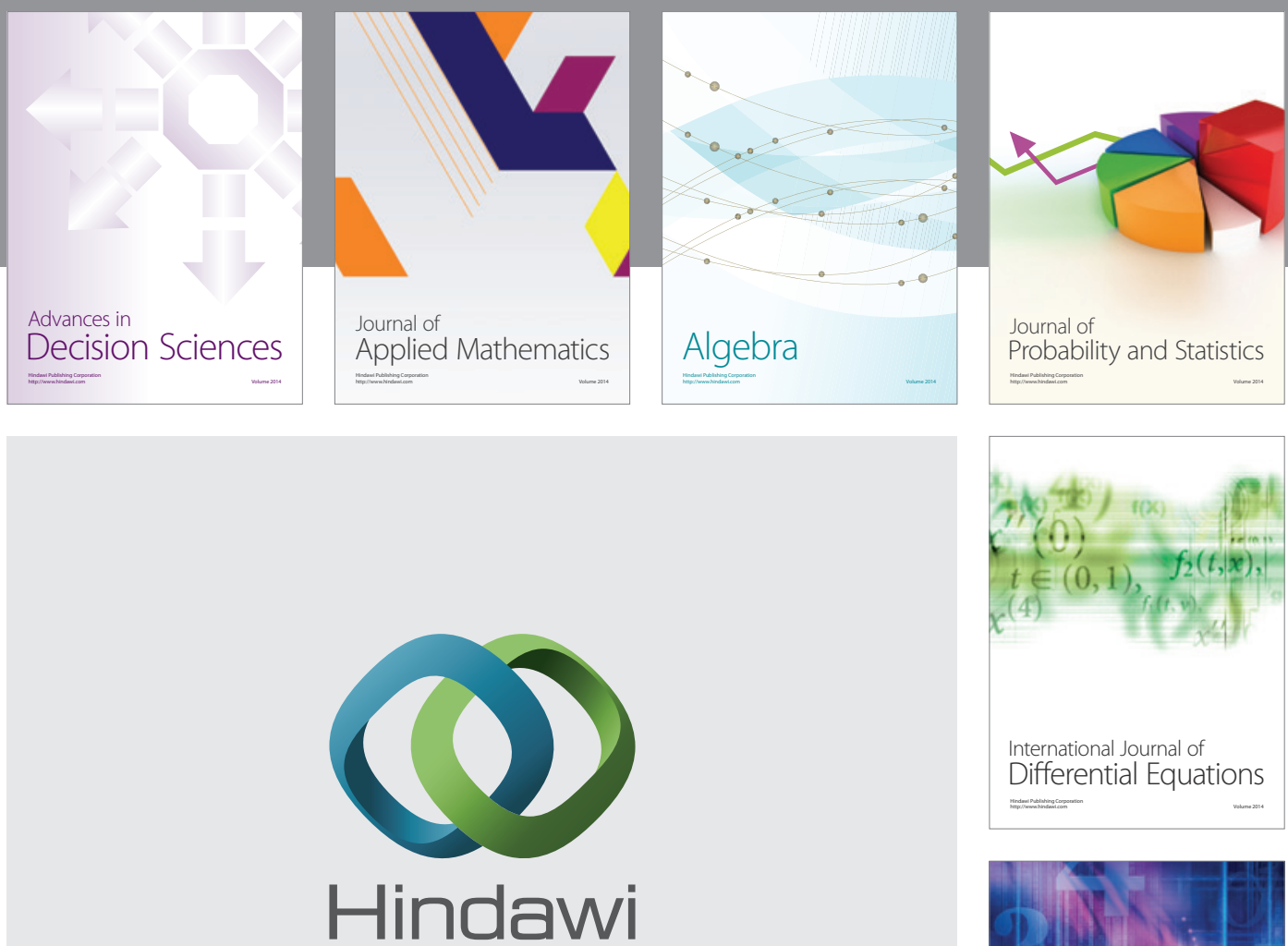

Submit your manuscripts at http://www.hindawi.com
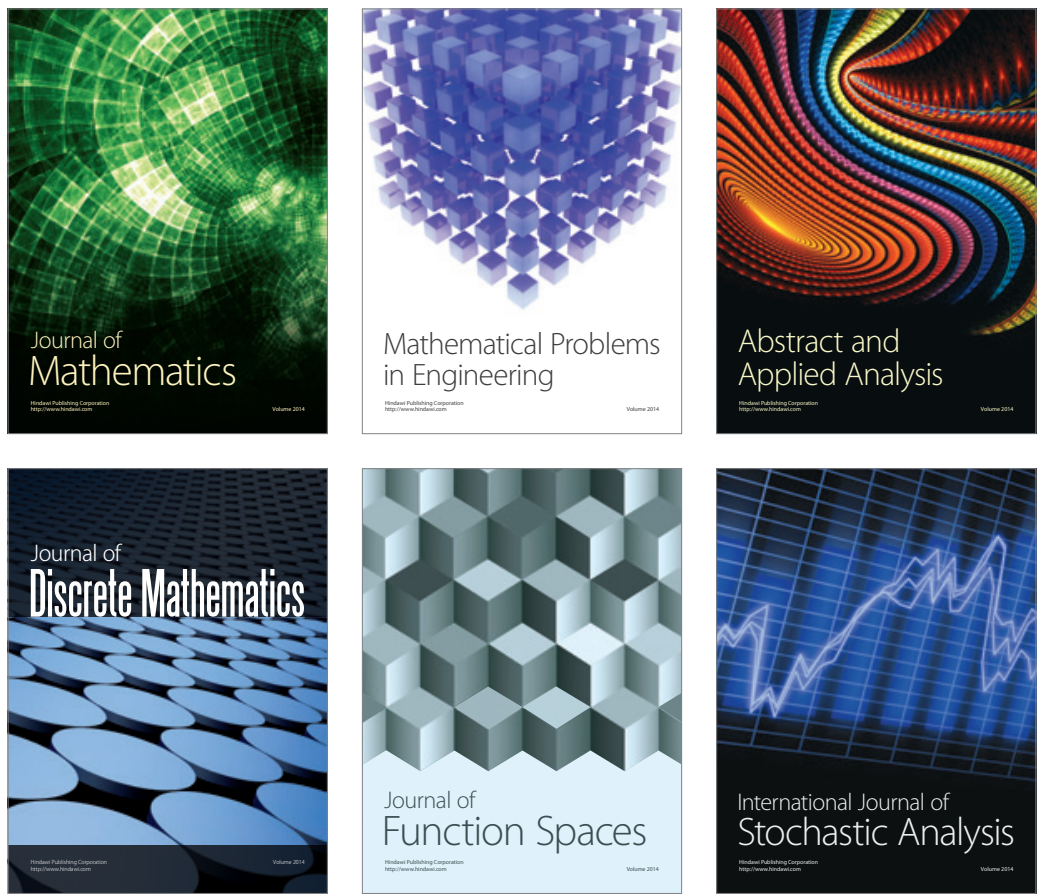

Journal of

Function Spaces

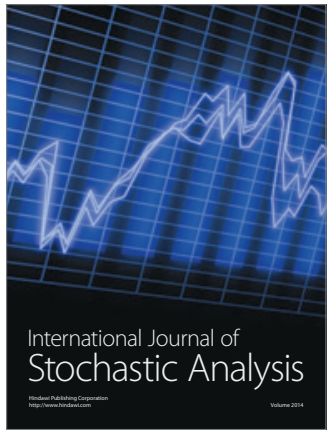

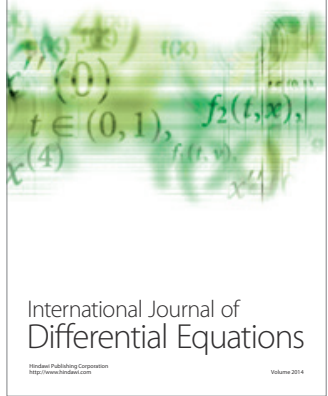
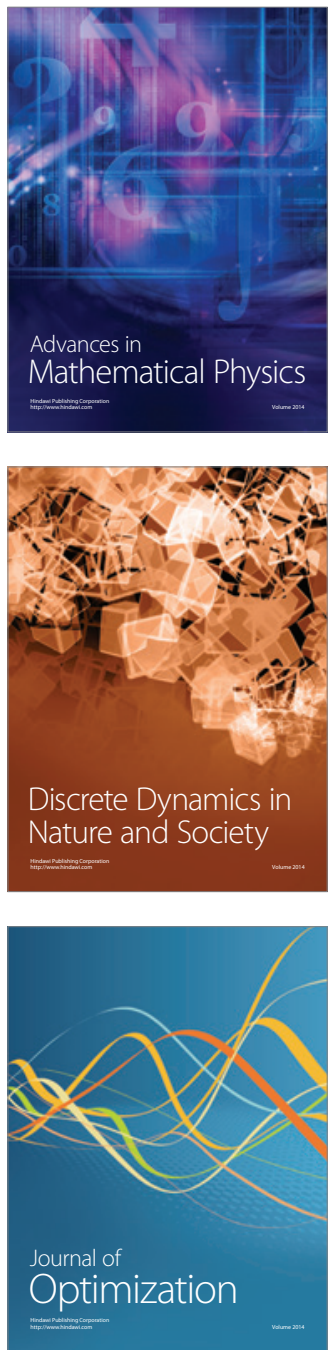